\title{
On Chinese-English Language Contact through Loanwords
}

\author{
Kui Zhu \\ College of Literature and Law, Sichuan Agricultural University \\ Ya'an 625014, Sichuan, China \\ E-mail: zk7660@126.com
}

\author{
Received: May 28, 2011 \\ Accepted: June 28, 2011 \\ Published: December 1, 2011 \\ doi:10.5539/ells.v1n2p100 \\ URL: http://dx.doi.org/10.5539/ells.v1n2p100
}

Foundation item: one of the projects funded by Sichuan Research Centre of Foreign Languages and Literature and Shanghai Foreign Language Education Press (license number: SCWYH10-35)

\begin{abstract}
All communities are involved in correlations with other communities, which leads to frequent contact between societies. And inevitably this contact breeds the borrowing of words between languages. In other words, there appear a great number of loanwords in any language and this is especially true for English and Chinese. This paper is concerned about loanwords in English and Chinese, and the characteristics of their language contact, thus further promoting language contact between these two languages and the communication between China and other English-speaking countries.
\end{abstract}

Keywords: English, Chinese, Loanwords, Language contact

Since the 1980s, China has experienced increasingly frequent contacts with other countries, especially English-speaking countries. "The necessities of intercourse bring the speakers of one language into direct or indirect contact with those of neighboring or culturally dominant languages... Whatever the degree or nature of contact between neighboring peoples, it is generally sufficient to lead to some kind of linguistic inter-influencing" and "the simplest kind of influence that one language may exert on another is the "borrowing' of words" (Sapir,1921). English is the most significant international language in science, technology, sports and entertainments and the contact between Chinese and English inevitably breeds their mutual borrowing of words. There are many researches on the loanwords domestically and abroad, of which typical ones are Chinese Borrowings in English (Cannon, 1988), A Study of Lexical Borrowing from Chinese into English with Special Reference to Hong Kong (Chan et al, 1985), Chinese Loanwords (Shi, 2000), Sources of Chinese Borrowing in English (Wang et al, 2001), Language Fusion of Chinese Loan Words from English and English Loan Words from Chinese (Chen, 2009) and etc.. But there's not much on the comparison of the borrowings and the characteristics of their mutual contact. With more and more frequent contact, loanwords will become a typical linguistic phenomenon, so the study on loanwords will be of great importance not only to the use of loanwords, but to the language contact and cultural communication between China and English-speaking countries.

\section{English Loanwords in Chinese Language}

\subsection{Brief introduction of English loanwords in Chinese language}

Word borrowing from English has a long history in the development of Chinese language. But foreign words began to wave into Chinese vocabulary from the late $19^{\text {th }}$ century to the early $20^{\text {th }}$ century, during which Chinese people were suffering from both domestic cruel governing and foreign massive invasion. So many Chinese assumed that the only way to ease their abject misery was to learn from the western civilization. Representatives of these people were Liang Qichao, Kang Youwei and Yan Fu, who were dedicated to the study of foreign languages and cultures. With their great efforts, a great number of terms were introduced into Chinese vocabulary. Facing these loanwords, Chinese people have experienced some mental changes, the use of “火柴”(match), “石灰”(lime), “动物园”(zoo), “摩托车”(motorcycle) instead of “洋火”, “洋灰”, “万兽园”, “电驴” are indicative of their typical responses to the new things (Chen, 2005). But when the real climax came after China's implementation of the Reform and Opening-up policy, they get quite calm, tolerant, and even eager for new things. As a result, loanwords and their exotic flavor enjoy great popularity in Chinese language and among Chinese people. 


\subsection{Features of English loanwords in Chinese language}

\subsubsection{Covering a Wide Range}

In the daily life, loanwords can be perceived everywhere. Their wide use has facilitated the establishment of their own positions in Chinese vocabulary. Some of them even share certain similarities with Chinese native words, and people may even regard them as native ones. Therefore, loan items can be found in nearly all the aspects of Chinese culture (Tian, 2005). For example, 肯德基(Kentucky), 吐司(toast), 曲奇(cookie)(Shi, 2000), 绿色食品(green food), 雪碧(Sprite), 运动夹克衫(bi-swing) are related to food and clothing; 冷战(cold war), 外交(diplomacy), 泡沫经济(bubble economy), APEC/亚太经合组(APEC), 克隆(colon) and 电视电话(Videophone) express something about politics, economy, science and technology; 甲壳虫队(the Beetles), 家庭影院(home cinema), 肥 㿝剧(soap opera), NBA/美国职业篮球赛(NBA), 局点(game point), TOEFL(托福) are linked to art, entertainment and sports while 代沟(generation gap), 单身母亲(bachelor mother), IP卡(IP-card), 白领(white collar), 二手烟/ 被动吸烟(passive smoking) concern the concept of Western culture and life.

\subsubsection{English as the Largest Source Language}

English is the most widely used language in the world. It serves as the "lingua franca" for international business and cultural exchange. Just because of the special status of English, people from different countries and regions would like to choose English as their communicative language, thus further making English the most effective language. Since the implementation of China's Reform and Opening-up policy after 1978, a large number of foreign words have come into Chinese language and English has been the major source of all the borrowed words. There are 5218 entries in total borrowed from English according to Chinese Loanwords Dictionary, and among them 340 items have come into common use (Liu, 2004). With more and more international exchange, no one can deny that Chinese will borrow more and more words from English.

\subsubsection{Borrowed in Various Ways}

Those English words into Chinese lexical system help make the Chinese language richer and more expressive and they are imported in various ways:

(1) Transliteration, which means a foreign word is transcribed phonetically by Chinese characters (Huang, 2002), for example, coffee(咖啡), shock(休克), radar(雷达), Utopia(乌托邦), fans(粉丝), salad(沙拉), model(模特), golf (高 尔夫), humor(幽默), Olympic(奥林匹克) and etc.

(2) Free translation, with a borrowed word rebuilt by the Chinese phonemes and Chinese way of word formation without changing its English meaning(Zhang, 2002). Purify(净化), dictator(独裁), multimedia(多媒体), barcode(条 形码), penicillin(青霉素), computer(电脑), reflection(反映), soap-opera (肥㿝剧), democracy(民主), inspiration (灵感) are typical examples for this.

(3) Loan blend, which means one part is translated phonetically and the other part is translated according to its meaning (Huang, 2002), for example, 浪漫主义(romanticism), 苹果派(apple-pie), 蛋挞(egg tart), 呼啦圈 (hula-hoop), 文化休克(culture shock) are borrowed this way.

(4) Footnoted translation, which indicates the semantic class (the underlined part in the examples) is added to the borrowed word when it is translated into Chinese so that Chinese people can understand it better(Huang, 2002). 吉普 车(jeep), 芭蕾舞(ballet), 同性恋(homosexual), 艾滋病(AIDS), 白皮书(white paper), 卡宾枪(carbine) are some of the examples.

(5) Transplantation, which includes two types: one is made up of English acronyms, such as WTO, APEC, SOS, CD, MP3, PK; and the other category is a combination of both English initials and Chinese characters, examples are X光(X-rays), 卡拉-OK(Karaoke), B-超(type B Ultrasonic diagnostic machine), IP卡(Internet phone card), $\mathrm{pH}$ 值 ( $\mathrm{pH}$ value) and etc.

\section{Chinese Loanwords in English Language}

\subsection{Brief introduction of Chinese loanwords in English language}

It is believed that English began to borrow words from Chinese more than 1000 years ago. Oxford English Dictionary has made a strong proof to back up this point: the Chinese word "silk" was imported in English in 888 $\mathrm{AD}$ through the Silk Road. But the multitude of Chinese words introduced into English can only be dated back to Ming Dynasty when China was quite a prosperous country and an ideal destination for trade. Many English businessmen rushed to China for business and brought many Chinese specialties back to their own countries. From then on, the Chinese specialties have become more famous and their names have been used more frequently in people's conversations. Since the year 1949, great changes have taken place in China and there appear many new terms about China's politics, economy, science and technology, most of which have been introduced into English. 
These words have been kept down as loanwords by English speakers and they become an essential part of English vocabulary. Typical examples are the words with Chinese characteristics: tea, tofu, ketchup, litchi, yangko(秧歌), sanfan(三反), Renmin Ribao(人民日报), guanxi (关系), strike hard(严打), iron-rice bowl(铁饭碗) and etc.

In the course of borrowing, three methods are employed: transliteration, loan translation and loan blend (Li, 2004):

(1) Transliteration: chow fan(炒饭), yen(阴), typhoon(台风), mahjong(麻将), kung fu(功夫), Confucius(孔夫子), 舢板(sampan), ganbei/ can pei(干杯), ganbu(干部) and etc.

(2) Loan translation: bean curd(豆腐), chinaware(中国瓷器), the Xia Dynasty(夏朝), acupuncture(针尒), capitalist-roader(走资派), silkworm(寔), steamed bun(馒头), chopsticks(筷子), fire-cracker(爆竹), family planners(计划生育工作者).

(3) Loan blend: Tung oil(桐油), suona horn(唢呐), Beijing opera(京剧) and longjing tea(龙井), Maoist(毛泽东思想 的追随者) and Dengers(邓小平的追随者) are typical examples.

\subsection{Features of Chinese Loanwords in English Language}

\subsubsection{Accounting for only a Small Portion}

Compared with other languages, Chinese only contributes a small portion in English borrowings. English lexical system is a large container of foreign words and it has borrowed many words from other languages, such as Greek, Latin, French, etc. According to historical studies, English has borrowed words from dozens of languages and the borrowed words account for about $70 \%$ in English vocabulary. But the statistics from the Oxford Dictionary show that English has only borrowed about 1000 items from Chinese and they are mainly about Chinese food and traditional customs. And most of these words share Chinese pronunciations, and are generally made up of Chinese characters, for examples, zongzi(粽子), jiaozi(饺子), chow mein(炒面), spring roll(春卷), moon cake(月饼), spring festival(春节), dragon boat festival(龙舟节端午节), feng shui(风水), cupping (拔火罐), etc.

\subsubsection{Adopting Expressions Related to China for Chinese Loanwords}

English speakers prefer to use words related to China when referring to the Chinese borrowings. Typical examples are the words and expressions which contain the word "China," "Chinese" or are derived from the prefix "Sino-". Some of these words are presented here:

(1) Words composed of “China”: China bean(豇豆), China blue(中国蓝), China rose(月季花), China ink(墨水), China orange(橙子), Chink(中国佬), chinoiserie(中国艺术风格), altogether about 46 words. (Wang, 2001)

(2) Words composed of “Chinese”: Chinese jujube(诏书), Chinese lantern(灯笼), Chinese anise(茴香), Chinese calendar(农历), altogether about 128 words. (Wang, 2001)

(3) Words derived from “Sino-”: Sino-Mongolia(中蒙关系), Sinology(汉学), Sinologist(汉学家), Sino-phobia(恐 华，惧华), Sinophile (Sinophil) (亲华人士), Sinicize(使中国化) and etc.

\subsubsection{New Terms Coming into English at a Great Speed}

With the opening up of China, the communication between China and English-speaking countries have been promoted and more terms with Chinese Characteristics have been employed in people's talks and they come into English at a great speed. There are words about China's modern society, for example, open door policy(开放政策), one country, two systems(一国两制), special economic zone(经济特区), Project Hope(希望工程), Western Development Strategy(西部开发),Three Represents' Theory(三个代表), Shenzhou V(神舟V号), taikonaut (from Chinese word "taikong" and English word "astronaut), Chindia(from the word "China" and "India"), Chimerica (from the word "China" and "America") and etc. According to Global Times, about 20,000 new words were added to English in the year 2005, among which 4,000 is from Chinese. (Chen, 2009)

\section{Characteristics of Language Contact between Chinese and English}

From the above discussion, it is clear that both Chinese and English have loanwords from each other. This mutual lexical borrowing carries the following characteristics:

\subsection{Character of integration}

Every speech community learns from others. When there is cultural borrowing, there is always the likelihood that the associated words may also be borrowed. As far as cultural borrowing is concerned, all languages are equal and have the same chance to lend to, or to borrow from all or most of other languages ( $\mathrm{Hu}, 2002)$. With the increase of communication between English and Chinese and further development of China, more and more borrowed words have appeared in these two languages. Many of these borrowed words are frequently used in people's conversations and have gradually been absorbed. Once they become members of their vocabulary, it is not easy for users to tell 
whether they are borrowed or not.

\subsubsection{English Assimilated into Chinese}

The development of China and English-speaking countries has made language contact of these two languages more frequent and has created many loanwords. Observations indicate that almost all the Chinese people, whether the old or the young, men or women, do know such English words or expressions as "Bye-Bye," "OK," "Daddy," "Mummy," "Yes", "No", which have become household words in their daily lives. Moreover, with the popularity of English films, music and international games as well as the great demand of information exchange, more and more English words and terms are blended into Chinese. Therefore, English letter words such as SOS, MTV, and WTO have gained comparatively wide acceptance because of their convenience and efficiency. So many foreign words have been frequently used that they are felt to be part of the Chinese language. Therefore, the foreign origin of the words might not even be suspected, and certainly could not be proved, without the speakers' explicit statements about their foreignness. In other words, the English words have been Chinesized in the process of borrowing. As is known, foreign words are transformed into various new forms that can be perceived by different hosts, which leads to various versions of the same foreign words. But not all the variants can survive because the variants differ in their degree of "fitness", i.e., adaptation to the Chinese social cultural environment. Fitter variants will be more successful in being communicated, influencing a large number of individuals and surviving for a longer time within the population. Hence, foreign words without being naturalized by Chinese were rejected by native-speakers of Chinese and it was hard for Chinese to assimilate the words in Chinese community, and those survived have become part of the Chinese vocabulary without being regarded as weird or clumsy by the general public. A typical example is the word “telephone”, which was once translated as “德律风”, “德利风”, “电话”, but only “电话” survived and it has completely assimilated into Chinese.

\subsubsection{Chinese Assimilated into English}

People can often hear English speakers utter words tinted with Chinese pronunciation. And the listeners would not be surprised or confused. To many English speakers, these words of Chinese pronunciation are too familiar for them to pay extra attention to. Generally speaking, words referring to Chinese food and customs are frequently used in English speakers' conversations and they are regarded as a daily must. The open character of English vocabulary system indicates that it will absorb more Chinese words, and the development of China poses an external force for it to import more Chinese items. Words like China, Chinese, china, Sino and Tao have not only been indexed in English vocabulary, but help form a lot more new words.

In brief, the mutual-borrowing between Chinese and English consequently leads the characters of the two languages to be well integrated with each other.

\subsection{Character of asymmetry}

As is known, English and Chinese have their respective writing system. English adopted a sound writing system, which has dominated most of the world languages. This makes it convenient for English to borrow from these world languages. But Chinese adopted a word writing system and few languages in the world adopted this system. In this case, it is difficult for Chinese to borrow from other languages. Therefore, there is asymmetry embodied in its number, fields and frequency of their use.

\subsubsection{In terms of the Number of Loanwords}

According to the previous studies, it is clear that English has much fewer Chinese loanwords in its lexical system than English loanwords in Chinese. According to Garland Cannon (1988), English has in total 1189 Chinese loanwords in its vocabulary. On the other hand, Chinese have brought in many more English words and English is the major source language in terms of loanwords in Chinese. It is said that there are 5218 English loanwords in the Chinese Loanwords Dictionary. The sharp contrast in numbers obviously indicates the asymmetry between English loanwords in Chinese and Chinese loanwords in English, chiefly due to the great influence that English has exerted on Chinese and its status of being the world's "lingua franca."

\subsubsection{In terms of Fields Covered by Loanwords}

English borrows not only heavily but also extensively. And there are some distinctive features of asymmetry in terms of fields covered by English loanwords in Chinese and Chinese loanwords in English. On one hand, the majority of the Chinese loanwords in English are related to Chinese culture, customs, specialties and philosophy. Here are some examples: Taiji Quan(太极拳); Double Ninth Day(重阳节), chopsuey(杂碎), Taoism(道教), etc. On the other hand, loanwords from English cover almost all aspects of Chinese society, ranging from IT fields like CPU, internet(英特网) to the daily expressions such as cigar(雪茄) and taxi(的士). 


\subsubsection{In terms of the Frequency of their Use}

There is a sharp contrast in the use frequency between English loanwords in Chinese and Chinese loanwords in English. For one thing, English shares the same writing system with many languages in the world and it is convenient for it to borrow words from the same system. Chinese' quite unique family background leads to great differences between Chinese and English, which pushes English speakers to borrow more words from the same family. Besides, Chinese loanwords are not very frequently used in English speakers' conversations except when they are talking about topics concerned with China. For another, for the time being, English culture enjoys greater popularity than Chinese culture and English language has the largest group of users in the world, so the influence of English has poured more words of its lexicon into Chinese society and forces Chinese people to involve more English words into their daily communications.

\subsection{Character of plasticity}

Language is always changing. As Sapir has put it, "Languages, like culture, are rarely sufficient unto themselves."(Sapir, 1921) In the process of mutual lexical borrowing between English and Chinese, plasticity can be perceived. Chinglish is a typical example.

Because Chinese people have quite different patterns of thinking, it is sometimes difficult or impossible for them to accept the standard English of English-speaking countries. Besides, there is great gap between English culture and Chinese culture, so those Chinese who speak English may express the typical Chinese culture in their special way when receiving foreign guests, negotiating with foreign business partners or introducing Chinese culture. With time passing by, these expressions become acceptable and therefore Chinglish has been created. Most scholars have reached an agreement that Chinglish is a variant form of English which refers to things and phenomena of Chinese character, and they are built on the basis of Standard English. According to Joan Pinkham, Chinglish is neither English nor Chinese, but might be described as "English with Chinese characteristics" (Pinkham, 2000).

Although Chinglish is just a variant form of English and still in its infancy, it is an inevitable trend that more and more Chinglish words will be used in communication between Chinese people and English speakers for the following reasons. First, Chinglish words have their unique meanings and help make English more expressive. Second, when these words are borrowed into English, they have only one meaning and are less likely to be interpreted in other ways, therefore, they are easy to learn. Third, their meanings are comparatively stable, without any extension of meaning, thus making it convenient to be used. Besides, with the development of China's economy and society, the status of Chinese language will undoubtedly be promoted to a higher position. Chinglish will not only be more acceptable to English speakers but also become a must for the communication between China and English-speaking countries and the symbol for China's development (Chan et al. 1985).

Language is never static and English is no exception. The emergence of Chinglish is a typical case that English has the plasticity to be changed to a form that contains elements of Chinese characteristics. Moreover, Chinglish can also be viewed as an indication that Chinese also possesses the character of plasticity. That's to say, it can also follow the rules of Standard English expressions.

\section{Conclusion}

Language is the vehicle of culture and is in the constant evolution and development. So where there is cultural exchange, there is language contact and lexical changes. In cultural exchange, English has become an international language, which not only helps fill the semantic gap, but also communicates western culture to people all over the world.

Chinese language has experienced a long history and has become one of the languages that can express exact and clear ideas and there is no denying that it will develop more quickly. As is known, China is getting stronger and stronger, foreign people are becoming more interested in Chinese and more Confucius Schools are being opened in the world. So we have good reasons to believe that in the contact with the outside world, Chinese language will be able to play the same role as English- developing itself and most important of all, strengthening the language contact between China and other countries, thus spreading the essence of Chinese culture to the world.

\section{References}

Cannon, G. (1988). Chinese Borrowings in English. American Speech, 63(1), 3-33. The University of Alabama Press.

Chan, Mimi, \& Helen Kwok. (1985). A Study of Lexical Borrowing from Chinese into English with Special Reference to Hong Kong. Hong Kong: University of Hong Kong Center of Asian Study. pp. 16-20

Chen, Chuanli, \& Gao, Jixian. (2009). Language Fusion of Chinese Loan Words from English and English Loan 
Words from Chinese. Journal of Qujing Normal University, 28(2), 91-95. http://dx.doi.org/0.2009-02-024

Hu, Zhaoyun. (2002). Language Contact and Lexical Borrowing of English and Chinese: A Comprehensive Study. Jinan: Shandong University Press. pp. 77

Huang, Borong, \& Liao, Xudong. (2002). Modern Chinese. Beijing: Higher Education Press. pp. 313-314

Li, Xiaofei. (2004). Infiltration of Culture by Borrowed Words into English and Chinese. Shandong Foreign Language Teaching Journal, 1, 47-49. http://dx.doi.org/1002-2643.0.2004-01-011

Liu, Yanshi. (2004). Study of Borrowed Words into English and Chinese Through Cultural Contact. Journal of the Chengdu Municipal Party College of C.P.C., 12 (6), 64-65. http://dx.doi.org/1008-679x.0.2004-06-025

Pinkham, J. (2000). The Translator's Guide to Chinglish. Beijing: Foreign Language Teaching and Research Press.

Sapir, E. (1921). Language. New York: Harcourt, Brace and Company. pp. 205

Shi, Youwei. (2000). Chinese Loanwords. The Commercial Press. pp. 284

Tian, Hui. (2005). On Cultural Communication by Borrowed Words into English and Chinese. Journal of Xiangtan Normal University (Social Science Edtion.), 27(4), 103-106. http://dx.doi.org/1009-4482.0.2005-04-033

Wang, Rongpei, \& Chang, Junyue. (2001). Sources of Chinese Borrowing in English. Journal of Sichuan International Studies of University, 17(4), 70-73. http://dx.doi.org/1003-3831.0.2001-04-019

Zhang, Bin. (2002). Newly Compiled Modern Chinese. Shanghai: Fudan University Press. pp. 247-248 